\title{
PERFIL EPIDEMIOLÓGICO E AVALIAÇÃO DA RESPOSTA AO TRATAMENTO CIRÚRGICO NOS PACIENTES COM ESPONDILODISCITE ATENDIDOS NO SERVIÇO DE CIRURGIA DA COLUNA DO HOSPITAL GETÚLIO VARGAS EM RECIFE/PE
}

EPIDEMIOLOGIC PROFILE AND ASSESSMENT OF RESPONSE TO SURGERY IN PATIENTS WITH SPONDYLODISCITIS IN THE DEPARTMENT OF SPINE SURGERY AT HOSPITAL GETULIO VARGAS IN RECIFE/PE

\author{
PERFIL EPIDEMIOLÓGICO Y EVALUACIÓN DE LA RESPUESTA AL TRATAMIENTO \\ QUIRÚRGICO EN PACIENTES CON ESPONDILODISCITIS TRATADOS EN EL SERVICIO DE \\ CIRUGÍA DE LA COLUMNA DEL HOSPITAL VARGAS EN RECIFE/PE
}

\begin{abstract}
Jocemir Paulino da Silva Junior¹, André Flávio Freire Pereira², Leonardo de Lima Silveira³, Marcus André Costa Ferreira² Túlio Albuqueroue de Moura Rangel ${ }^{2}$
\end{abstract}

\begin{abstract}
RESUMO
Objetivo: Analisar a epidemiologia da população acometida por espondilodiscite e avaliar a resposta ao tratamento cirúrgico . Método: Foram avaliados 13 pacientes, sendo três do sexo feminino e 10 do sexo masculino, com diagnóstico de espondilodiscite e tratados cirurgicamente no período de outubro de 2007 a janeiro de 2010. A média da idade no momento da cirurgia foi de 54 anos. Foram analisados os prontuários e entrevistados os pacientes, considerando-se os seguintes parâmetros: gênero, faixa etária, etiologia, nível comprometido, sintomatologia, tempo de evolução até a cirurgia, alterações neurológicas, tratamento realizado, complicações pós-operatórias e evolução clínica. Resultados: O sexo masculino foi mais acometido, assim como indivíduos mais idosos; a dor na região comprometida foi o sintoma inicial em $80 \%$ dos pacientes. O tempo médio entre o inicio dos sintomas e o tratamento cirúrgico foi de 20,25 meses. O segmento lombar foi o mais acometido, seguido pelo torácico e toracolombar, e a forma piogênica foi a mais frequente. O procedimento em dois tempos cirúrgicos pela via posterior (VP) e via anterior (VA), foi utilizado em 53\% dos pacientes. Conclusão: Os pacientes do sexo masculino e os idosos foram os mais acometidos. O tratamento cirúrgico em dois tempos foi seguro e apresentou menor morbidade para os pacientes com espondilodiscite.
\end{abstract}

Descritores: Tuberculose/epidemiologia; Discite; Infecção; Artrodese.

\begin{abstract}
Objective: To analyze the epidemiology of population affected by spondylodiscitis and to evaluate the response to surgical treatment in these patients. Method: Thirteen patients, three females and ten males with a diagnosis of spondylodiscitis treated surgically in the Department of Spine Surgery at Getulio Vargas Hospital from October 2007 to January 2010 were evaluated. The mean age at surgery was 54 years. The medical records were analysed and the patients were interviewed, to check the following parameters: gender, age, etiology, compromised level, symptoms, duration until surgery, neurological disorders, treatment, postoperative complications and clinical outcome. Results: Male were more affected, as well as older individuals, being pain in the affected region the initial symptom in $80 \%$ of patients. The average time between onset of symptoms and surgical treatment was 20,25 months. The lumbar segment was the most affected, followed by thoracic and thoracolumbar ones, and pyogenic form was the most frequent.. The surgical procedure in two stages via posterior (VP) and via anterior (VA), was used in 53\% of patients. Conclusion: Patients were male and the elderly were the most affected. The surgical treatment in two stages is safer and has less morbidity for patients with spondylodiscitis.
\end{abstract}

Keywords: Tuberculosis/epidemiology; Discitis; Infection; Arthrodesis

\section{RESUMEN}

Objetivo: Analizar la epidemiología de la población afectada por espondilodiscitis y evaluar la respuesta al tratamiento quirúrgico en estos pacientes. Método: Trece pacientes, tres mujeres y diez hombres con diagnóstico de espondilodiscitis tratados quirúrgicamente en el Departamento de Cirugía de Columna del Hospital Getulio Vargas de octubre de 2007 a enero de 2010. La edad promedio de pacientes sometidos a la cirugía fue de 54 años. El historial clínico fue analizado y se entrevistó a los pacientes, comprobándose: sexo, edad, etiología, nivel de peligro, los síntomas, la duración hasta la cirugía, trastornos neurológicos, tratamiento, complicaciones posoperatorias y los resultados clínicos. Resultados: Los varones fueron más afectados, así como las personas ancianas, el dolor en la región afectada fue el síntoma inicial en el $80 \%$ de los pacientes. El tiempo promedio entre la aparición de los síntomas y el tratamiento quirúrgico fue 20,25 meses. El segmento lumbar fue el más afectado, seguido el por torácico y el toracolumbar, y se presentaron en el formulario piógenos más frecuentes. El procedimiento en dos etapas: posterior (VP) y anterior (VA), se utilizó en el 53\% de los pacientes. Conclusión: Los pacientes del sexo masculino, ancianos, y de más bajo nivel socioeconómico son los más afectados. El tratamiento quirúrgico en dos etapas es más seguro y tiene menos morbilidad en los pacientes con espondilodiscitis.

Descriptores: Tuberculosis/epidemiología; Discitis; Infección; Artrodesis.

1. Ortopedista eTraumatologista do Hospital da Restauração - Recife (PE) Brasil

2. Ortopedista eTraumatologista, Cirurgião de Coluna do Hospital Getúlio Vargas - Recife (PE) Brasil

3. Ortopedista eTraumatologista do Hospital Getúlio Vargas - Recife (PE) Brasil

Trabalho realizado no Serviço de Cirurgia da Coluna do Hospital Getúlio Vargas, Secretaria Estadual de Saúde de Pernambuco, Recife/PE.

Correspondência: Avenida Senador Ruy Carneiro, 853 Apt 502, Miramar, João Pessoa/PB. Brasil. CEP: 58032-901. E-mail: jocemir@ hotmail.com 


\section{INTRODUÇÃO}

A espondilodiscite piogênica e a tuberculosa são doenças graves da coluna vertebral que frequentemente provocam o aparecimento de dor e o desenvolvimento de deformidade cifótica pela perda do suporte anterior do segmento vertebral coluna ${ }^{1}$

O objetivo do tratamento da espondilodiscite, seja tuberculosa ou piogênica, é erradicar a infecção e prevenir ou tratar a deformidade, instabilidade e o déficit neurológico ${ }^{2}$. No passado, pacientes com espondilodiscite eram frequentemente tratados com repouso no leito, antibioticoterapia e imobilização com órteses ${ }^{3,4}$. A opcão pelo tratamento cirúrgico para a espondilodiscite é realizada nos pacientes com instabilidade pronunciada, deformidade acentuada da coluna vertebral, sintomas neurológicos progressivos com evidência de compressão das estruturas neurológicas, presença de abscesso ou nos pacientes em que o tratamento conservador não resulta em bom resultado ${ }^{5}$.

No Serviço de Cirurgia da Coluna do Hospital Getulio Vargas, na cidade do Recife, tem sido evidenciado um número cada vez maior de pacientes acometidos pela espondilodiscite, e que necessitam de tratamento cirúrgico.

As infecções da coluna vertebral são causadas por vários agentes etiológicos, sendo os bacterianos os mais importantes, dentre eles o Staphylococcus Aureus que é o mais frequente ${ }^{6}$. No entanto, a tuberculose também constitui um importante fator etiológico da espondilodiscite?

A tuberculose é uma doença infecciosa comumente observada nos países em que a superpopulação e a desnutrição são problemas frequentes, e a sua incidência tem crescido com o aumento de pacientes imunocomprometidos ${ }^{8}$. $\mathrm{O}$ acometimento osteoarticular atinge aproximadamente $10 \%$ desses pacientes e a metade deles pode ter envolvimento da coluna vertebral ${ }^{9}$.

O diagnóstico e tratamento precoce são essenciais para a obtenção de resultados satisfatórios. O tratamento cirúrgico precoce previne a deterioração neurológica e a progressão da deformidade cifótica ${ }^{10}$.

Há na literatura escassez de estudos sobre o tratamento cirúrgico utilizando uma técnica em dois estágios, com operações por via posterior (VP) e via anterior (VA) em dois tempos ${ }^{11}$. Daí a importância da avaliação, nesse estudo, dentre outros aspectos, dos resultados obtidos com essa técnica cirúrgica

Este trabalho tem por objetivo realizar a avaliação epidemiológica dos pacientes portadores de osteomielite da coluna vertebral e submetidos a tratamento cirúrgico, num serviço terciário na cidade do Recife.

\section{MÉTODO}

Este estudo é uma análise epidemiológica de pacientes com osteomielite da coluna vertebral, piogênica ou tuberculosa, no Hospital Getulio Vargas no período de outubro de 2007 a janeiro de 2010. Durante o período foram admitidos 13 pacientes que foram submetidos a tratamento cirúrgico no serviço. Sendo o tratamento cirúrgico realizado em um ou dois tempos.

Um formulário especifico para a pesquisa foi preenchido durante a internação e seguimento dos pacientes. No formulário de pesquisa foram relacionados aspectos epidemiológicos tais como idade, gênero, presença de comorbidades, história prévia de tuberculose, nível acometido, status neurológico no momento do diagnóstico, tempo da sintomatologia, e abordagem terapêutica realizada.

Todos os pacientes foram avaliados inicialmente com imagens de radiografias em incidências anteroposterior e lateral da coluna vertebral, para determinação do nível da lesão, extensão do acometimento ósseo e presença de deformidade. Foram obtidas também imagens de Tomografia Computadorizada, Ressonância Magnética com contraste. Além de exames laboratoriais como velocidade de hemossedimentação (VSH), leucograma e dosagem de Proteína C reativa $(\mathrm{PCR})$, para controle da resposta a terapêutica antibiótica instituída, foi também realizada a cultura, antibiograma e anátomopatológico do tecido obtido durante o desbridamento cirúrgico.

As indicações para o tratamento cirúrgico foram: falha do tratamento conservador, grande destruição do segmento vertebral acometido, sinais de instabilidade (colapso maior que 50\% do corpo vertebral ou destruição ou deformidade cifótica localizada maior que 11 graus na coluna cervical e maior que 20 graus na coluna torácica e lombar, segundo o método de Cobb) e/ou alterações neurológicas (deterioração neurológica aguda, paraparesia e paraplegia).

Os seis pacientes com diagnóstico de espondilodiscite por tuberculose foram submetidos ao esquema tríplice (Rifampicina, Isoniazida e Pirazinamida - RIP) por um período de nove meses. Os sete pacientes com espondilodiscite piogênica foram tratados com antibióticos específicos por um período médio de 11,25 semanas.

\section{RESULTADOS}

A tabela 1 apresenta os dados dos pacientes do estudo.

A idade média dos pacientes foi de 54 anos (desvio padrão de 17,5 anos), com a idade mínima 29 e máxima de 81 anos. Os pacientes idosos foram os mais acometidos. A distribuição nas diferentes faixas etárias está representada na figura 1

Três pacientes eram do sexo feminino e 10 do sexo masculino (Figura 2).

Quanto ao agente etiológico, seis pacientes tiveram diagnóstico estabelecido de espondilodiscite tuberculosa, e os sete restantes classificados como piogênica (Figura 3), nos quais o agente etiológico identificado foi o Staphylococcus aureus em três pacientes um apresentou flora mista (Klebsiella spp., Proteus spp., e Staphylococcus coagulase negativo e três não tiveram o agente etiológico identificado. Culturas negativas foram obtidas em $23 \%$ dessa série de casos, taxa consistente com as de outras investigações anteriores ${ }^{11,12}$

Com relação ao segmento vertebral acometido, a coluna lombar foi mais acometida(38\%) que a coluna torácica (31\%) e a transição tóraco- lombar (23\%), havendo apenas um paciente com lesão da coluna cervical (8\%) e um paciente com dois níveis acometidos (Figura 4).

Quanto a sintomatologia no momento do diagnóstico, em dez dos 13 pacientes (77\%) a dor na região acometida foi a queixa inicial, um paciente inicialmente alterações neurológicas, um iniciou com febre seguida de dor na região acometida três dias depois e outro com o surgimento de aumento de volume na região lombar associada a queda do estado geral e febre com evolução de três semanas (Figuras 5, 6, 7 e 8). Dos dez pacientes que apresentaram dor como queixa inicial três apresentaram febre e perda de peso associada, outros três pacientes apresentaram apenas perda de peso associada. Febre como sintoma isolado foi observado em um paciente e dois apresentaram a dor como sintoma isolado. Destes dez pacientes, três evoluiram com alterações neurológicas.

Nos pacientes estudados o tempo entre o aparecimento dos primeiros sintomas e tratamento cirúrgico (considerando a data da primeira cirurgia ), variou de um mês a 11 anos (média de 20,25 meses). Uma paciente permaneceu com alterações neurológicas por cerca de onze anos antes de ser submetida ao tratamento cirúrgico. Os demais pacientes foram operados com menos de 18 meses de evolução.

Tabela 1. Dados dos pacientes dos estudos, idade, gênero, nível acometido e etiologia

\begin{tabular}{c|c|c|c|c|c}
\hline Caso & Idade & Gênero & Segmento Envolvido & Tuberculosa & Piogênica \\
\hline 1 & 29 & $\mathrm{~F}$ & T12-L1 & & $\mathrm{X}$ \\
\hline 2 & 30 & $\mathrm{M}$ & T6-T10 & $\mathrm{X}$ & \\
\hline 3 & 34 & $\mathrm{M}$ & T8-T11 & $\mathrm{X}$ & \\
\hline 4 & 31 & $\mathrm{M}$ & L1-L2 & & $\mathrm{X}$ \\
\hline 5 & 68 & $\mathrm{~F}$ & T11-T12 & $\mathrm{X}$ & \\
\hline 6 & 81 & $\mathrm{M}$ & L3-L4 & & $\mathrm{X}$ \\
\hline 7 & 68 & $\mathrm{M}$ & T12-L1 & $\mathrm{X}$ & \\
\hline & & & L5-S1 & & \\
\hline 8 & 68 & $\mathrm{M}$ & C4-C5 & $\mathrm{X}$ & \\
\hline 9 & 50 & $\mathrm{M}$ & L4-L5 & & $\mathrm{X}$ \\
\hline 10 & 61 & $\mathrm{M}$ & T8-T9 & $\mathrm{X}$ & \\
\hline 11 & 57 & $\mathrm{~F}$ & L4-L5 & & $\mathrm{X}$ \\
\hline 12 & 61 & $\mathrm{M}$ & T12-L1 & & $\mathrm{X}$ \\
\hline 13 & 64 & $\mathrm{M}$ & L3-L4 & & $\mathrm{X}$ \\
\hline
\end{tabular}




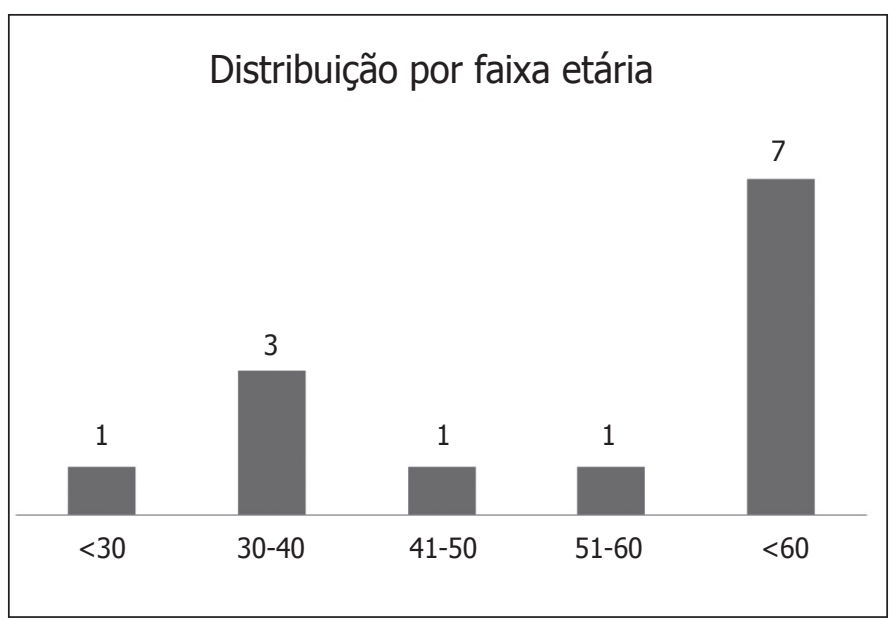

Figura 1. Distribuição da doença nas diferentes faixas etárias.

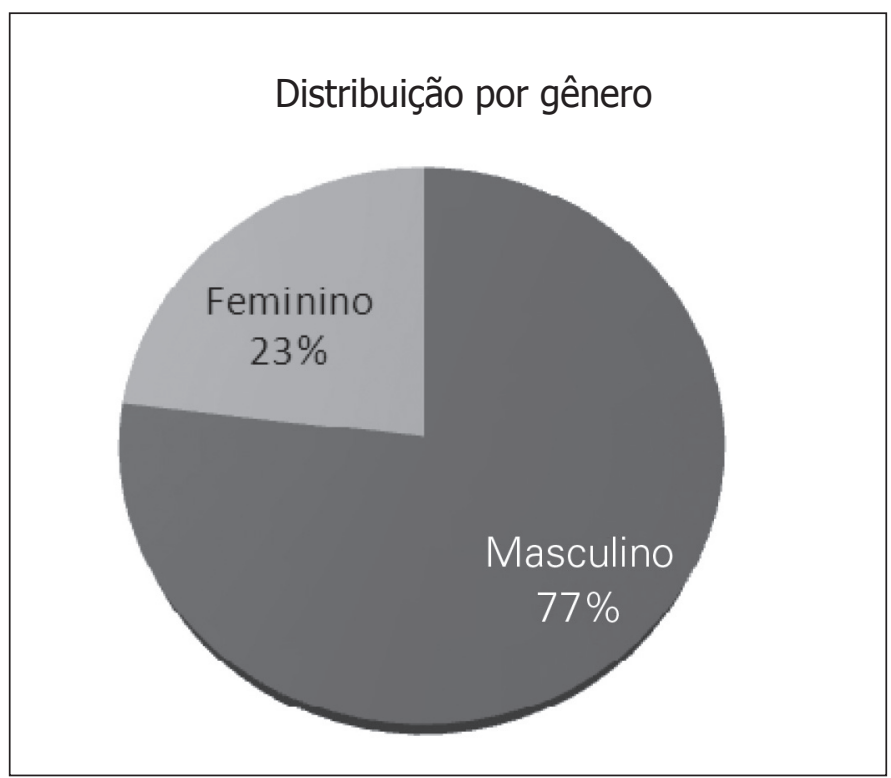

Figura 2 - Distribuição dos pacientes de acordo com o sexo

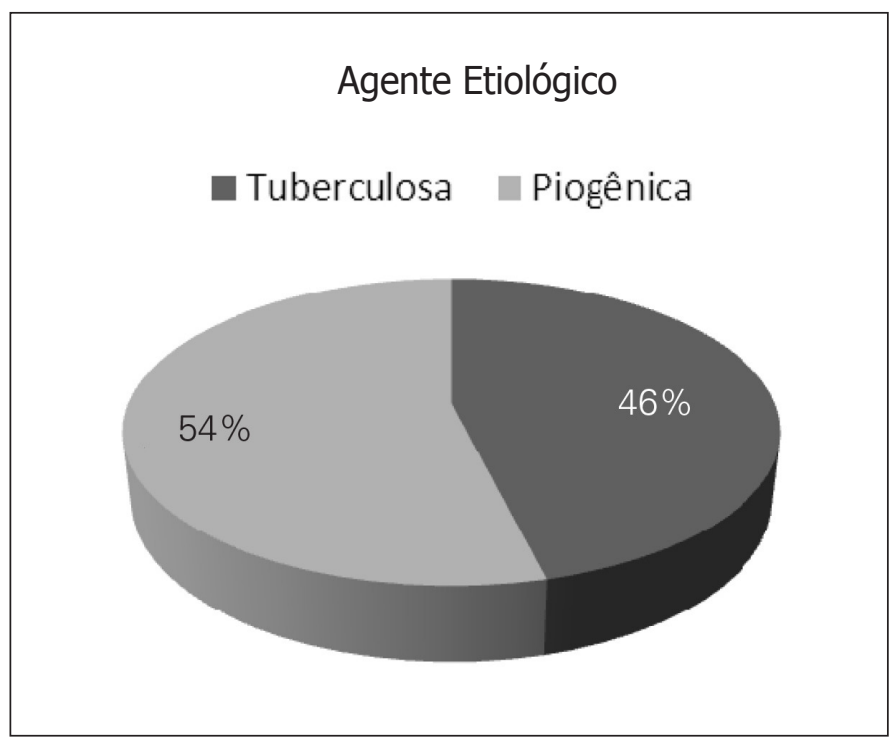

Figura 3. Distribuição dos pacientes de acordo com a etiologia.

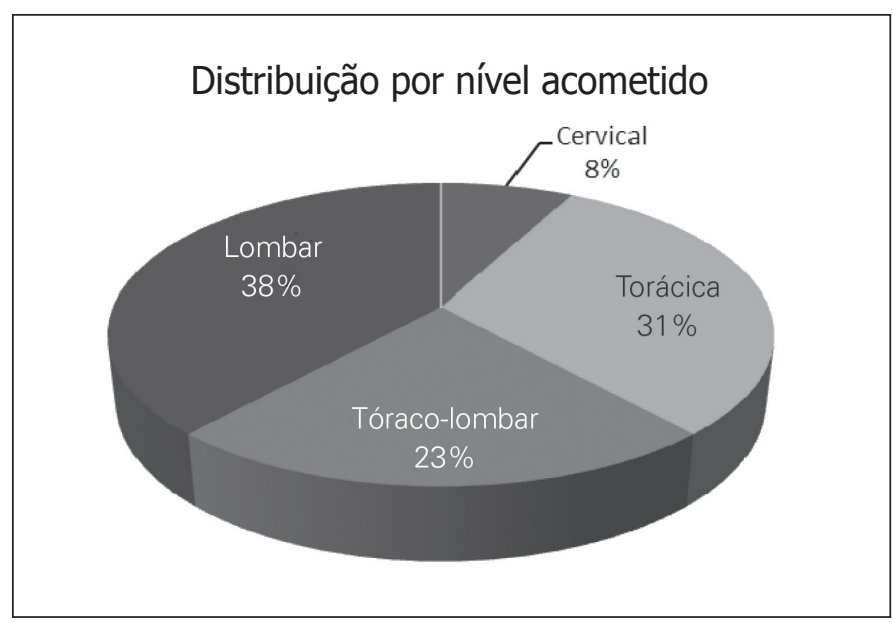

Figura 4. Distribuição dos pacientes de acordo com o segmento vertebral acometido.

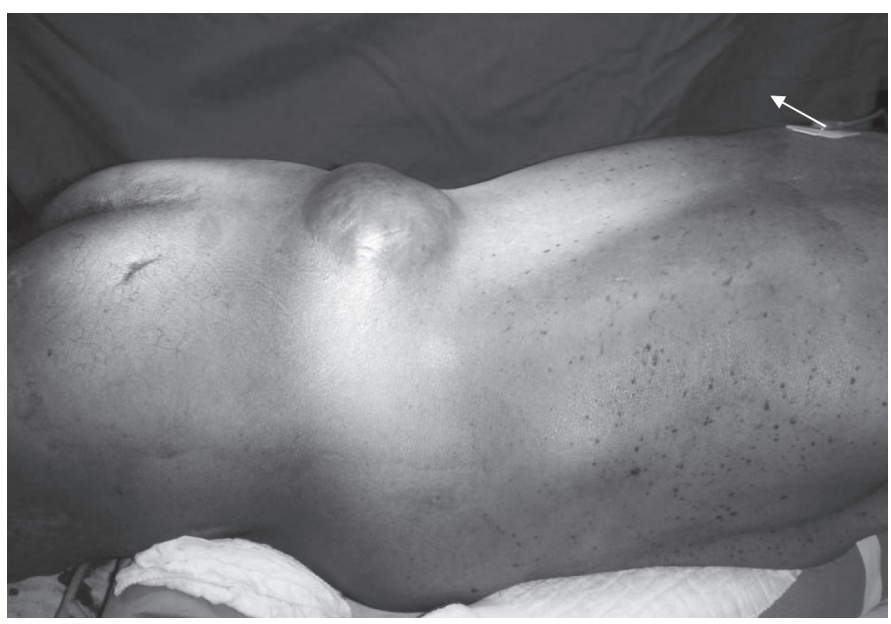

Figura 5. Aspecto clínico de abscesso por espondilodiscite

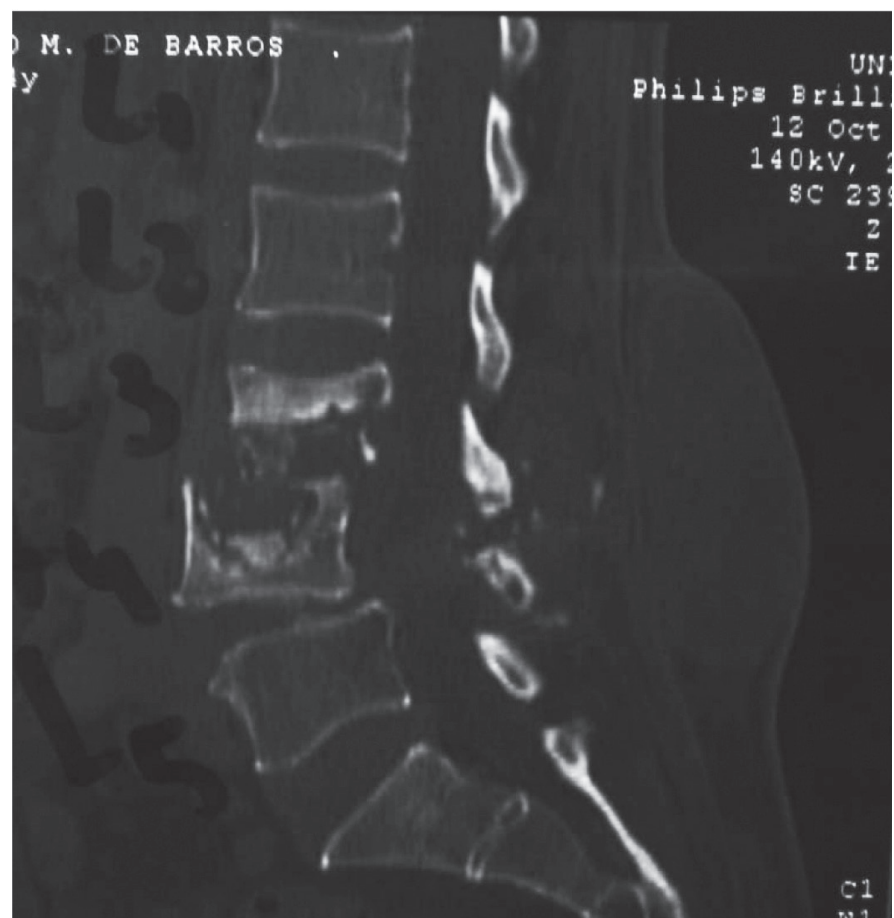

Figura 6. Corte sagital de tomografia computadorizada evidencia a lesão do espaço discal e corpos vertebrais contíguos 


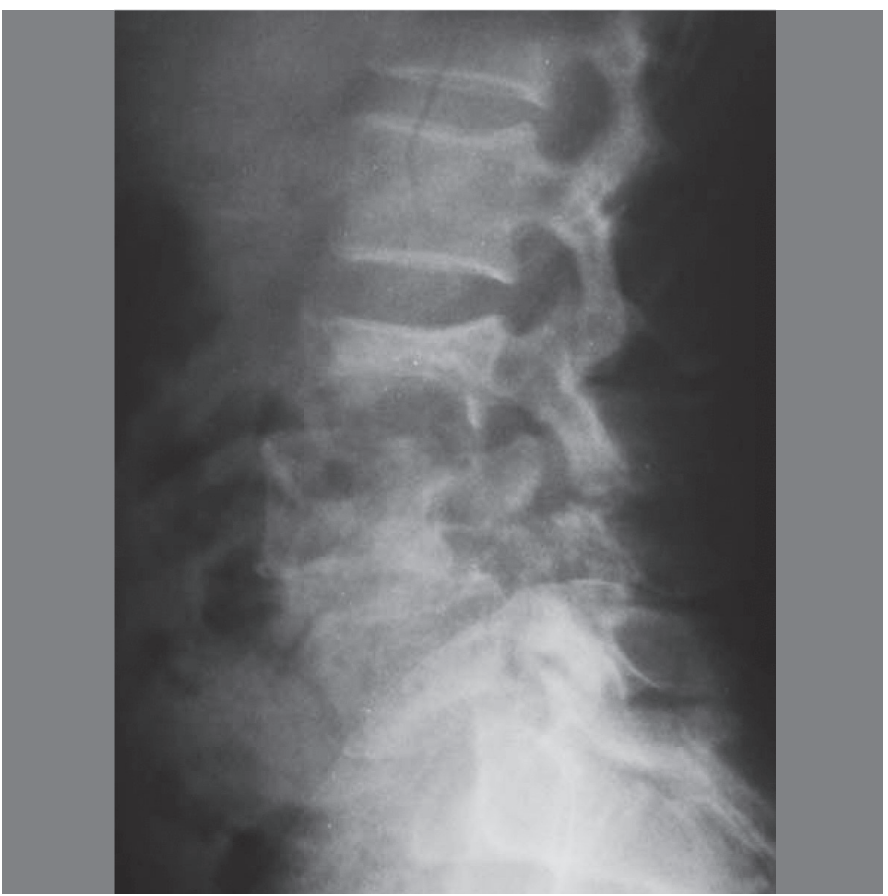

Figura 7. Radiografia em perfil de lesão do espaço discal e corpo vertebral

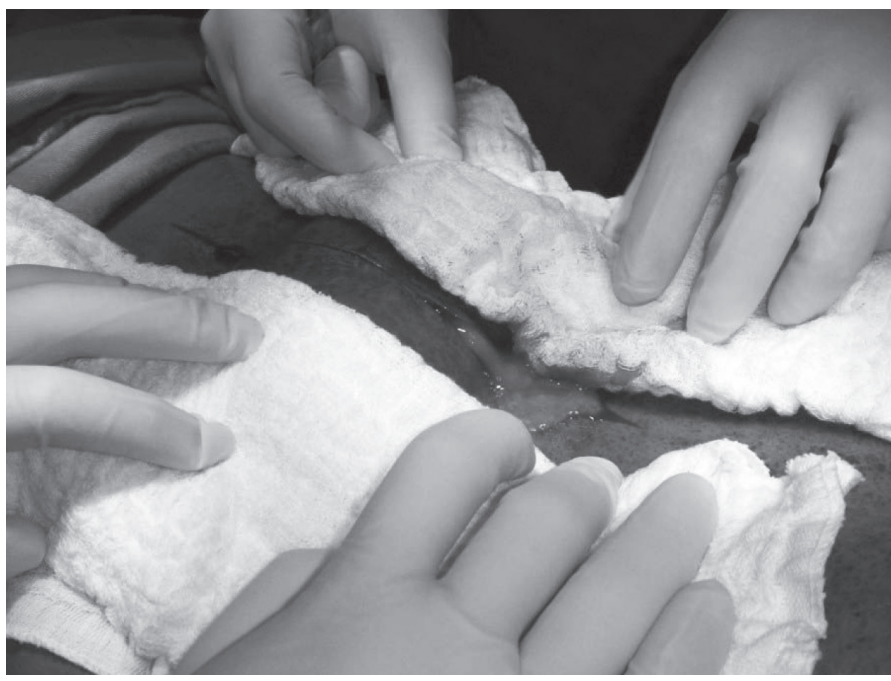

Figura 8. Aspecto intraoperatórios de abscesso por espondilodiscite incisão da via de acesso.
A análise laboratorial avaliando os marcadores de atividade inflamatória, a média da VSH antes da primeira cirurgia foi de 40,75 mm/h (variando de 09 a 65 mm/h). A média da VSH ao final do seguimento pós-operatório para os dez pacientes nos quais ela foi medida foi de $43,75 \mathrm{~mm} / \mathrm{h}$ (variando de 25 a $55 \mathrm{~mm} / \mathrm{h}$ )

A média da PCR antes do primeiro procedimento cirúrgico para os oito pacientes nos quais ela foi medida foi de 196,75 mg/L (variando de zero a $768 \mathrm{mg} / \mathrm{L}$ ). A média da PCR ao final do seguimento pós-operatório para os dez pacientes nos quais ela foi medida foi de $31,41 \mathrm{mg} / \mathrm{L}$ (variando de zero a $96 \mathrm{mg} / \mathrm{L}$ ).

A PCR foi mais fidedigna como critério de cura de osteomielite mostrando a tendência de retorno aos níveis normais ( $<6,5 \mathrm{mg} / \mathrm{L})$; no entanto a VSH não apresentou retorno aos níveis normais provavelmente em virtude de processos inflamatórios em outros locais ou outras doenças sistêmicas

A via posterior (VP) associada à via anterior (VA) foi utilizada em sete pacientes em dois tempos cirúrgicos: na primeira cirurgia, para promover a estabilização do segmento vertebral acometido, e por ser uma cirurgia menos agressiva foi aplicada a VP utilizando parafusos pediculares e/ou ganchos sublaminares, sem entrar em contato com o sítio anterior infectado. As vias de acesso e evolução clínica dos pacientes estão relacionadas na tabela 2. Na segunda cirurgia foi utilizada a VA para o desbridamento e a colocação de enxerto. Um destes pacientes havia sido tratado apenas com artrodese por VP e evoluiu, 11 meses depois, durante o acompanhamento ambulatorial, com soltura da instrumentação posterior; tendo sido foi submetido à VA para artrodese com enxerto ósseo 386 dias depois da VP. Essa ocorrência conduziu ao aumento, da média de intervalo de tempo entre a realização das abordagens pela VP e VA. O intervalo médio entre a primeira e a segunda cirurgias dos seis pacientes considerados foi de 101,83 dias (variando de 11 a 386 dias).

A artrodese por VP isoladamente foi utilizada em seis pacientes. Em cinco destes casos a VA não foi utilizada devido às dificuldades relacionadas à via de acesso. Os pacientes evoluíram com fusão e anquilose anterior e resolução clínica das dores. No sexto caso somente a VP foi necessária para promover estabilidade suficiente ao segmento acometido. Em todos foi realizado o desbridamento por via transforaminal.

Um dos pacientes foi submetido à artrodese por VA antes da VP, com intervalo de 42 dias entre as duas cirurgias.

O enxerto utilizado nas cirurgias de VA foi retirado do ilíaco (tricortical) em $50 \%$ dos pacientes (quatro pacientes) e de costela em 50\% dos casos (quatro pacientes) e na VP foi resultado da decorticacão das facetas articulares e do processamento das apófises espinhosas. Segundo De Kemp et al ${ }^{13}$, o enxerto que promove maior fusão é o autólogo do ilíaco. Nessa série observou-se fusão em todos os pacientes submetidos à VP + VA, independentemente do tipo de enxerto utilizado. O paciente número 10 apresentou deterioração da função neurológica, desenvolvendo quadro de paraplegia, e recidiva da infecção dois níveis acima do segmento abordado inicialmente, sendo submetido a descompressão e desbridamento no novo sítio e extensão da instrumentação, seis meses após a cirurgia inicial, e apresentou melhora da função neurológica e da dor. Alterações neurológicas foram observadas em cinco (38\%) dos

Tabela 2. Período dos sintomas, abordagem cirúrgica, e quadro neurológico.

\begin{tabular}{|c|c|c|c|c|c|c|c|}
\hline Caso & $\begin{array}{c}\text { Sintomas até } 1^{\text {a }} \text { cirurgia } \\
\text { (meses) }\end{array}$ & Cirurgia & Enxerto Utilizado* & Vértebras artrodesadas & $\begin{array}{l}\text { Intervalo entre a } 1^{\mathrm{a}} \text { e } 2^{\mathrm{a}} \\
\text { cirurgias (dias) }\end{array}$ & Frankel Antes** & Frankel Depois** \\
\hline 1 & 132 & $V P+V A$ & Ilíaco & 2 & 143 & A & A \\
\hline 2 & 6,5 & $V P+V A$ & Costela & 7 & 18 & $D$ & $D$ \\
\hline 3 & 18 & $V P+V A$ & Costela & 9 & 386 & B & $E$ \\
\hline 4 & 2,5 & $V P+V A$ & Ilíaco & 4 & 11 & $E$ & $E$ \\
\hline 5 & 11 & VP & $x$ & 4 & $x$ & $E$ & $E$ \\
\hline 6 & 14 & $V P+V A$ & Ilíaco & 4 & 38 & $E$ & $E$ \\
\hline 7 & 6,5 & VP & $x$ & 4 & $x$ & $E$ & $E$ \\
\hline 8 & 2 & $V P+V A$ & Ilíaco & 4 & 15 & $E$ & $E$ \\
\hline 9 & 1 & VP & $x$ & 2 & $x$ & $E$ & $E$ \\
\hline 10 & 9 & $V A+V P$ & Costela & 6 & 42 & $E$ & $E$ \\
\hline 11 & 5 & VP & $x$ & 2 & $x$ & $E$ & $E$ \\
\hline 12 & 61 & VP & $x$ & 2 & $x$ & $\mathrm{D}$ & $E$ \\
\hline 13 & 64 & VP & $x$ & 4 & $x$ & D & $E$ \\
\hline
\end{tabular}


13 pacientes estudados. A escala de Frankel $^{14}$ foi utilizada para graduar estas alterações. Dos cinco pacientes, um apresentou-se como Frankel A no pré-operatório e manteve-se assim até o final do acompanhamento; o segundo foi admitido no hospital como Frankel D, apresentou melhora do grau de força de III para IV, mas não o suficiente para ser classificado como Frankel $E$, permanecendo assim como Frankel D e os demais evoluíram para Frankel $E$, sendo o de número 13 com evolução de Frankel D para $E$ no quinto dia pós-operatório.

Quanto a evolução clínica todos os pacientes apresentaram meIhora significativa das queixas iniciais ao final do acompanhamento, exceto o paciente número 10 , que, desenvolveu quadro de dor na ferida operatória na via de acesso anterior (neurite intercostal). $\mathrm{O}$ paciente número 06 faleceu devido a causa clínica não-relacionada com o tratamento cirúrgico, 11 meses após a primeira cirurgia; contudo estava completamente recuperado das queixas lombares em sua última visita ao ambulatório. O paciente número 13 apresentou quadro de acidente vascular encefálico isquêmico no $3^{\circ}$ dia de pós-operatório de seguimento ambulatorial. Nenhum paciente apresentou deterioração neurológica como complicação do tratamento cirúrgico. Não houveram complicações intra-operatórias.

\section{DISCUSSÃO}

Foi observada a predominância de espondilodiscite nos pacientes do sexo masculino, o que condiz com os achados de outros autores $3,11,15,17$. Nenhum paciente evoluiu com piora do estado neurológico após o tratamento cirúrgico, o que evidencia a segurança da técnica predominantemente utilizada de VP antes da VA.

A cirurgia pode ser realizada pela via anterior, posterior, ou duplavia. Durante o acesso anterior é realizada a discectomia, corpectomia parcial, em alguns casos, e a enxertia óssea, havendo a vantagem da abordagem direta ao sítio infeccioso, o que promove a consolidação mais precoce, porém, está associada com aumento de morbidade relacionada a esta via de acesso***. Na nossa casuística os pacientes submetidos a artrodese por via posterior nos níveis lombares mais baixos, foi realizado o desbridamento cirúrgico pela via transforaminal.

Seguindo as diretrizes de Fukuta et a/ ${ }^{11}$, o procedimento cirúrgico realizado em duas fases (VP e depois VA), foi baseado em quatro princípios. Primeiro, a curta duração da cirurgia de VP e a pequena perda de sangue intra-operatória; a invasividade da cirurgia convencional combinada VA associada à VP num mesmo tempo pode ser diminuída dividindo-se o procedimento em dois estágios. Segundo, o uso de instrumentação posterior oferece ao paciente suficiente estabilidade, diminuindo a intensidade das dores e proporcionando a fusão óssea nas regiões infectadas como exemplo, seis dos pacientes do estudo necessitaram apenas da VP para o tratamento definitivo. Terceiro, o efeito de imobilização promovido pela instrumentação posterior durante a primeira cirurgia pode também ser útil em suprimir a infecção na região anterior devido à estabilização alcançada. Por último,

\section{REFERÊNCIAS}

1. Klöckner C, Valencia R. Sagittal alignment after anterior debridement and fusion with or without additional posterior instrumentation in the treatment of pyogenic and tuberculous spondylodiscitis. Spine (Phila Pa 1976). 2003;28(10):1036-42.

2. Eismont FJ, Bohlman HH, Soni PL, Goldberg VM, Freehafer AA. Pyogenic and fungal vertebral osteomyelitis with paralysis. J Bone Joint Surg Am. 1983:65(1):19-29.

3. Rezai AR, Woo HH, Errico TJ, Cooper PR. Contemporary management of spinal osteomyelitis. Neurosurgery. 1999;44(5):1018-25.

4. Sapico FL, Montgomerie JZ. Vertebral osteomyelitis. Infect Dis Clin North Am. 1990 ;4(3):539-50.

5. Abramovitz JN, Batson RA, Yablon JS. Vertebral osteomyelitis. The surgical management of neurologic complications. Spine (Phila Pa 1976). 1986;11(5):418-20.

6. Cahill DW, Love LC, Rechtine GR. Pyogenic osteomyelitis of the spine in the elderly. $J$ Neurosurg. 1991:74(6):878-86.

7. Buchelt M, LackW, Kutschera HP, Katterschafka T, Kiss H, Schneider B, et al. Comparison of tuberculous and pyogenic spondylitis. An analysis of 122 cases. Clin Orthop Relat Res. 199;(296):192-9.

8. Zaveri GR, Mehta SS. Surgical treatment of lumbar tuberculous spondylodiscitis by transforaminal lumbar interbody fusion (TLIF) and posterior instrumentation. J Spinal Disord Tech. 2009:22(4):257-62

9. Currier BL, Kim CW, Eismont FJ. Infections of the Spine. In: Herkowitz HN, Garfin SR, Eismont FJ, Bell GR, Balderston RA. Rothman-Simeone the spine. Philadelphia: Saunders Elsevier; 2006. p. 1265-1315

10. Lee JS, Suh KT. Posterior lumbar interbody fusion with an autogenous iliac crest bone graft como os elementos posteriores da coluna raramente são foco inicial da infecção, o tratamento cirúrgico em dois estágios (VP e VA) pode ser utilizado numa grande percentagem de pacientes com espondilodiscite piogênica ou tuberculosa. Não se pode afirmar que a combinação da VP com antibioticoterapia possa omitir a segunda cirurgia com desbridamento e enxerto ósseo. Sendo indispensável criteriosa avaliação das mudanças destrutivas na região anterior acometida, para definir a necessidade ou não do uso da VA com intuito de promover transmissão de carga entre as vértebras. As razões para a segunda cirurgia não são apenas para prover suficiente estabilidade, mas também para aplicar curetagem radical nas áreas infectadas. O objetivo da reconstrução é manter alinhamento, prevenir deformidades, alcançar fusão e descomprimir o canal.

A paraplegia foi relatada como complicação de VP sem instrumentação provocada por subluxação anterior ${ }^{15}$, o que mostra a importância da instrumentação para promoção da estabilidade.

Quando se realiza primeiro a cirurgia por VA para desbridamento e enxerto o paciente é submetido a um maior tempo cirúrgico e maior perda de sangue, apesar de terem sido descritos bons resultados com essa estratégia ${ }^{11,15,16}$. Nas situações em que a primeira cirurgia é a VP, menos agressiva e com tempo cirúrgico menor, obtém-se estabilização e redução importante da intensidade das dores, promovendo diminuição e algumas vezes até resolução da infecção anterior. O intervalo entre as duas cirurgias, diferentemente de se realizar ambas as vias em um único tempo, permite ao paciente recuperação parcial com melhora do estado geral. Haverá também, menor morbidade associada à VA subsequente. Estudo recente sugere o tratamento completamente por VP associada a fusão interssomática lombar transforaminal (TLIF), com resultados satisfatórios do ponto de vista de critérios funcionais e prevenção de deformidade cifótica ${ }^{8}$.

Przybylsky et a/ ${ }^{18}$ sugeriram que a exposição do paciente a dois procedimentos anestésicos oferece maior risco, contudo não foram observadas complicações decorrentes da repetição da anestesia geral neste estudo.

Os resultados indicam que pacientes com espondilodiscite tuberculosa ou piogênica podem ser beneficiados pela técnica em dois estágios, com a VP como abordagem inicial. Podendo ser utilizada inclusive em pacientes debilitados, em virtude da menor morbidade inerente à estratégia cirúrgica ${ }^{19}$.

\section{CONCLUSÃO}

O tratamento cirúrgico mostrou-se efetivo para o tratamento da espondilodiscite seja piogênica ou tuberculosa. Em alguns pacientes a via posterior associada à antibioticoterapia foi suficiente para recuperação completa. A técnica operatória em dois estágios (via posterior e via anterior) mostrou-se segura, promovendo pequena morbidade para os pacientes, o que se refletiu na redução mais rápida da intensidade das dores e consequentemente num período de recuperação mais curto. in the treatment of pyogenic spondylodiscitis. J Bone Joint Surg Br. 2006;88(6):765-70. 11. Fukuta $\mathrm{S}$, Miyamoto $\mathrm{K}$, Masuda $\mathrm{T}$, Hosoe $\mathrm{H}$, Kodama $\mathrm{H}$, Nishimoto $\mathrm{H}$, et al. Two-stage (posterior and anterior) surgical treatment using posterior spinal instrumentation for pyogenic and tuberculotic spondylitis. Spine (Phila Pa 1976). 2003;28(15):E302-8.

12. Emery SE, Chan DP, Woodward HR. Treatment of hematogenous pyogenic vertebral osteomyelitis with anterior debridement and primary bone grafting. Spine (Phila Pa 1976). 1989:14(3):284-91.

13. Kemp HB, Jackson JW, Jeremiah JD, Cook J. Anterior fusion of the spine for infective lesions in adults. J Bone Joint Surg Br. 1973;55(4):715-34.

14. Barros EM, Taricco MA, Oliveira RP. Traumatismo raquimedular. In: Lech O, Barros Filho TEP, organizadores. Exame físico em ortopedia. 2a. ed. São Paulo: Sarvier; 2002. p. 76-81.

15. Hadjipavlou AG Mader JT Necessary JT, Muffoletto AJ. Hematogenous pyogenic spina infections and their surgical management. Spine (Phila Pa 1976). 2000 Jul;25(13):1668-79.

16. Yamada T, Mizuno J, Matsushita Y, Nakagawa H. Two-staged operation for thoracolumbar osteomyelitis following methicillin-resistant staphylococcus aureus infection of a craniectomy wound--case report. Neurol Med Chir (Tokyo). 2001;41(6):325-9.

17. Wood II GW. Infeccão da coluna vertebral. In: Canale ST. Cirurgia Ortopédica de Campbell. Tradução: Pinheiro, MFO, Oliveira, NG. 10a. ed. São Paulo: Manole. 2006. p. 2029-60

18. Przybylski GJ, Sharan AD. Single-stage autogenous bone grafting and internal fixation in the surgical management of pyogenic discitis and vertebral osteomyelitis. J Neurosurg. 2001:94(1 Suppl):1-7.

19. Ha KY, Shin JH, Kim KW, Na KH. The fate of anterior autogenous bone graft after anterior radical surgery with or without posterior instrumentation in the treatment of pyogenic lumbar spondylodiscitis. Spine (Phila Pa 1976). 2007 Aug;32(17):1856-64 